\title{
Initiation of Pharyngeal Swallow with Bolus Head in Valleculae
}

National Cancer Institute

\section{Source}

National Cancer Institute. Initiation of Pharyngeal Swallow with Bolus Head in Valleculae. NCI Thesaurus. Code C127221.

A finding of pharyngeal swallow initiated with bolus head in valleculae. 